\title{
EXITT-A Simulation Model of Occupant Decisions and Actions in Residential Fires
}

\author{
BERNARD M. LEVIN \\ Center for Fire Research \\ National Bureau of Standards \\ Gaithersburg, Maryland 20899, USA
}

\section{ABSTRACT}

EXITT is a discrete event simulation of occupant decisions and actions in a postulated fire. To run the model the physical descriptions of a residence, a specific fire in that residence, and the assumed occupants of the residence are entered into the computer. Based on a large set of decision rules, the occupants "make" decisions which are a function of the smoke conditions in the building, the characteristics and status of the occupants (including their capabilities), and the available travel routes. The occupants investigate the fire, alert and assist others, and evacuate the building. The simulation ends when all the occupants are either out of the building or are trapped by the smoke.

\section{BRIEF DESCRIPTION OF THE MODEL}

The EXITT model simulates occupant decisions and actions in fire emergencies in small residential buildings. In assigning decisions to an occupant, the computer considers such factors as: age of occupant; sex; whether the occupant is asleep; smoke conditions; whether any smoke detector is sounding and how loud it sounds; and the location, capabilities, condition and status of the occupants. This version of the model does not consider the heat or toxic components of the smoke.

The user controls the interactive version of the model through the keyboard by answering simple questions that appear on the screen. The decisions of the occupants are reported on the screen and on the printer. The movements of the occupants are displayed graphically on the screen, reported on the printer, and stored in a data file. The user can suppress outputs on the printer and on the screen.

Al1 the decision rules programmed in the model are designed to make the decisions as similar as possible to those that building occupants make in fire emergencies. The decision rules are based on: 1 , a limited number of controlled experiments; 2 . case studies of occupant actions in residential fires; and 3 . the judgment of the author. Whenever the rules are based directly on data in the literature or specific case studies, reference is made to such data. Otherwise, the rules are based on the author's judgment. 
Imbedded in the decision rules are parameters that can be easily changed. Developing improved values for these parameters is a major part of the future development of the model.

The permitted actions include: investigate the fire; alert others; awake others; rescue others; and evacuate/escape. Actions not permitted in the current version include: telephoning the fire department from within the building; fighting the fire; and re-entering the building to make a second rescue.

The simulation is currently being developed as a series of progressively more sophisticated models. This paper describes an early interactive version of the model which is designed to run on the IBM-PC computer (and similar microcomputers using the MS-DOS operating system) using the BASICA programing language. ${ }^{1}$

A more extensive description of the model, including a users's guide, is available from the author and from the Center for Fire Research. [Levin, 1987].

\section{SIMPLE EXAMPLE}

The following is a very simple example to illustrate the model. The building layout is shown in Figure 1. All bedroom doors are open. A smoke detector is located in the hall at node 7 . A father is sleeping in room 1 and a baby is sleeping in room 2. A small fire is in the living room, room 4. The major events are:

Smoke detector sounds at 90 seconds.

Father starts investigating at 100 seconds.

Father arrives at node 16 at 106.3 seconds. Sees moderate smoke at node 19 . End of investigation.

Father starts going to rescue baby at 109.3 seconds. (Since father has seen moderate smoke, his travel speed is increased.)

Father arrives at baby in room 2 at 113.6 seconds.

Father starts to carry baby to front door at 117.6 seconds. (Father travels at slower speed when carrying baby.)

Father and baby go through moderate smoke in living room and leave by front door (node 9 ) at 127.5 seconds.

If the smoke in the living room had been bad, the father and baby would have left by a window. If the adult was the mother instead of the father, she would have rescued the baby without having investigated first.

${ }^{1}$ The use of company names or trade names within this paper is made only for the purpose of identifying those computer hardware or software products with which the compatibility of the programs of EXITT has been tested. Such use does not constitute any endorsement of those products by the National Bureau of Standards. 


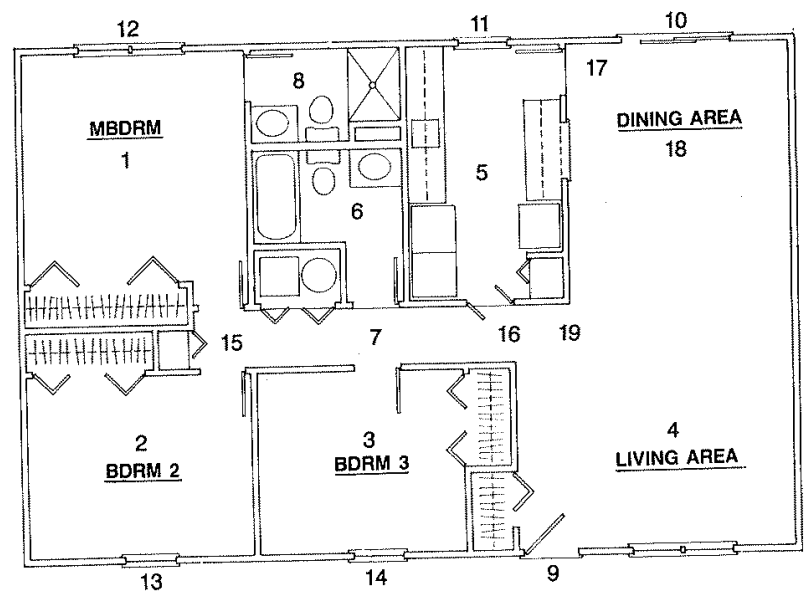

Figure 1. Floor Plan of a Typical Ranch House

\section{INPUT VARTABLES AND PARAMETERS}

Source of Data. The fires, buildings and occupants that are modelled can come from three sources: 1. three buildings--each with two or more fires and two or more sets of occupants-are stored in the computer programs and associated data files; 2 . the user can substitute a new building, fire and/or set of occupants by answering a large number of simple questions appearing on the screen; and 3. a new fire-e.g. the results of running a computer model such as FAST [Jones, 1984]--can be added. The user can change the value of some of the parameters by answering questions that appear on the screen. Changing other parameters requires simple changes in the program.

Building. The building is represented within the computer by nodes that represent rooms, exits and secondary locations within rooms; and by links or distances between adjacent nodes. The major data used to define a building are: the number of rooms, nodes and exits; the height of each room; the room location of each node; nature of each exit (door or window); and the distances between adjacent nodes. Windows that cannot be used in a fire are not entered into the computer as exits.

Smoke. The program is designed to use the output of the FAST model [Jones, 1984]--or any other similar model--for distributing smoke throughout the building over time. EXITT assumes a two layer smoke model. However, it is assumed that a small proportion of the smoke in the upper layex gets into the lower layer so that there is an odor of smoke in the lower layex. ExITT accepts as input the smoke density in the upper layer and the depth or height of the two layers in each room at the beginning of each time period, e.g., every five seconds.

The measure of smoke density for which the model is being calibrated is a commonly used measure of smoke density. It is the one used by Jin in his studies of human behavior in smoke [Jin, 1976].

$O D=\ln \left(I_{0} / L\right)$ 
where $L_{0}$ is the initial light intensity which reduces to a value of $L$ over a path of one meter. This measure is consistent with the well recognized fact that when people perceive a physical stimulus, the perceived intensity tends to vary directly with the 1 og of the physical intensity of the stimulus.

One important factor in making action choices in a residential fire is the properties of the smoke in the occupant's room. A measure of the psychological impact of smoke is determined as follows:

$\mathrm{S}=2 * \mathrm{OD} * \mathrm{D} / \mathrm{H} \quad$ where,

$S$ is the psychological impact of the smoke.

OD is the optical density of the smoke in the upper layer,

$D$ is the depth of the upper layer, and

$\mathrm{H}$ is the height of the room.

This expression is based on the assumption that the impact varies directly with the smoke density (i.e., the log of the concentration of smoke in the upper layer) and with the depth of the upper layer. The formula is an arbitrary representation of this assumption.

Decision rules and definitions that involve $\mathrm{S}$ include:

Occupants will not move to a node where $S>0.5$ (or into a room where $\mathrm{S}>0.4$ ) unless the depth of the lower layer (H-D) is at least 1.2 meters, i.e., unless the occupant can crawl under the smoke.

Occupants will increase their travel speed by $30 \%$ after encountering a room where $\mathrm{s}>0.1$.

Occupants will terminate an investigation if they are in a room where $s>0.05$. They will terminate their investigation before entering a room where $S>0.1$.

Once an occupant is in a room where $\mathrm{S}>0.1$, he wi11 respond more quickly: the changes are described below as consequences of believing the fire to be serious.

When $s>0.4$ there are prohibitions and penalties: these are described below as consequences of encountering "bad smoke."

Each of the above mentioned thresholds is an input parameter. Note that when the depth of the upper smoke layer is one half the room height, $S$ equals the smoke density of the upper layer. Jin found that people will escape a familiar building if the smoke density does not exceed 0.4 $-0.7 / \mathrm{m}[\mathrm{Jin}, 1976]$. The choice of starting the prohibitions and peralties at $S=0.4$ is consistent with a conservative interpretation of Jin's data for irritating smoke. All these parameter values will be reconsidered as part of further development of the model.

Noise and Alarm. The background noise level in a room affects the ability of an occupant to hear the alarm, both in real fires and in the model. Its default value is 35 decibels. Another input, related to a specific fire scenario, is the loudness of each smoke detector in each room, including the room in which it is located.

Characteristics of the occupants. The characteristics of the occupants are: age; sex; normal travel speed; whether or not the occupant needs help in evacuation; whether or not the person is awake; room location; and, if the occupant is asleep, a measure of how difficult it is for the occupant to awaken. 
Introduction. There are two types of occupants: those who are fully capable when awake and those who need assistance in moving. The decision rules apply only to those who are capable when awake. Those who need assistance moving make no decisions and their movements are determined by their "rescuer".

At the beginning of the simulation, all occupants are unaware of the fire and the potential danger. Actions and decisions are assigned, in part, based on the smoke conditions in each room at the beginning of the appropriate time period.

The following paragraphs describe the sequential steps the computer follows in determining the decisions and actions of one occupant for one time period. The computer goes through these steps for each capable occupant for the first time period and then repeats the process for each subsequent time period, in turn, until all the occupants are either out of the building or trapped by the fire. (For each step, the computer considers all occupants before proceeding to the next step.)

Aware of Fire. An occupant becomes aware of the fire when the fire cues are sufficiently strong. Obviously, stronger cues are needed to awaken and alert a sleeping occupant than to alert an awake occupant. The fire cues are: the sound of the smoke detector; the odor of smoke; and, for awake occupants, visible smoke and visible flame. If the weighted sum of the intensities of the cues reach a prescribed threshold, the occupant will be flagged as being aware of the fire cues. (If the fire cues are of borderline intensity, the occupant will become awake and aware after an assigned delay.)

The following basic equation, for determining if and when an occupant will start to respond to the fire cues, was suggested by the empirical results of Nober et al.[1981]. While Nober studied only the response of the smoke detector alarm, his results were generalized for the odor of smoke, and the sight of smoke.

$\mathrm{T}=70-4(\mathrm{C}-20)$

and

$\mathrm{C}=(\mathrm{A}-\mathrm{N})+\mathrm{X} 1+\mathrm{X} 2+\mathrm{X} 3+\mathrm{X} 4$

where,

$T$ is the delay time, in seconds, before the occupant will start his first action;

$C$ is the sum of the sensory impacts on the occupant;

A is the sound intensity of the smoke detector as heard by the occupant,

$N$ is the background noise;

$\mathrm{X} 1$ is impact of an awake occupant seeing flame.

$\mathrm{X} 2$ is impact of an occupant smelling smoke--it is a function of the smoke density and smoke depth and applies to both sleeping and awake occupants.

$\mathrm{X} 3$ is impact of an awake occupant seeing smoke--it is a function of $s$.

$X 4=0$ if the (typical) occupant is asleep and $X 4-15$ if the occupant is awake. This reflects the fact that more stimuli are required to wake than to alert an occupant. The value of 15 is based on the data in Nober [Nober et al, 1981]. 
Subject to the restrictions:

$A-N$ cannot be less than zero. If $N>A$ let $A-N=0$;

$\mathrm{T}>=$ an assigned minimum time to wake up or become aware of the fire cues, select an action, and perform preparatory actions. These minimum times range from 1 to 10 seconds depending on whether the occupant is asleep and the amount of smoke.

If $\mathrm{C}<20$ then $\mathrm{T}=$ infinity (i.e., 99999 in the computer). This restriction is based on Nober's data where occupants usually either responded within 70 seconds or remained asleep for the remainder of the test period.

$X 1$ and $X 3$ equal zero if the occupant is asleep.

The model, as described above, assumes that the response is a function of the sum of the impacts of different sensory cues. This assumes that the relevant aspects of the perceptual processing of olfactory, visual and auditory cues are similar. There does seem to be a surprisingly consistent perceptual rule (Fechner's Law) that the intensity of a perception varies directly with the log of the physical stimulus. (While this rule has broad applicability, it is not universal and only approximate [Boring, 1950].) Since our measure of the psychological impact of all the cues are based on the $10 \mathrm{~g}$ of a physical measure, the impacts to the three types of cues can be assumed to be roughly comparable. The decision to sum the impacts of the three cues is based on the assumption that simple behavioral rules are better than complicated ones when there is no technical reason to select a complicated one. Furthermore, simple summing is consistent with the results of Fletcher and Munson who found that a tone heard binaurally seems twice as loud as the same tone heard monaurally [Licklider, 1951].

The physical measures of the fire cues are measured in different units and they must be converted to a single measure of sensory impact. It was decided to use "equivalent decibels" as the single measure of sensory impact. The impacts of the other sensory cues are "converted" to equivalent decibels, i.e., the values of $\mathrm{X} 2$ and $X 3$ are transformed to the number of decibels that would approximate an equivalent impact in alerting occupants. The transformation factors are input parameters: their values will be the subject of future research and analysis.

For each occupant, a time to start his actions is computed independently at each time period until the occupant starts his first action: that is, a different time to start his actions will be computed each time period. He will start his action at the earliest time among those computed.

Assigning Actions to Occupants Who Are Aware of Fire. If an occupant has been assigned an action in a previous time period, he will be given an opportunity to complete that action before any consideration is made regarding additional actions.

Investigation Top Priority. Levin analyzed records of in depth interviews of 105 victims of residential fires [Levin, 1985]. He classified the respondents into 4 categories based on their presumed initial interpretation of the fire:

A. Respondent believes there may be a fire.

B. Respondent believes it is likely there is a fire.

G. Respondent is sure there is a fire and has seen enough smoke to believe it is a dangerous fire. 
Action

Seek information

Call fire department

Alert others

Fight fire

Evacuate incapable

other

A
41
-
1
-
1
4

$B$
11
3
3
-
3
-

66 female

39 male

\begin{tabular}{crr} 
C & & D \\
\cline { 1 - 1 } 6 & & - \\
1 & & 4 \\
2 & & 5 \\
1 & & 11 \\
4 & & 2 \\
3 & & -
\end{tabular}

105 total

Figure 2. Relationship of First Action to the Interpretation of Fire Cues

D. Respondent has seen the flames: the fire may or may not be dangerous.

Figure 2 shows the relationship of the choice of first action to the interpretation of the cues.

Based on the strong tendency to investigate when the situation is unclear, the first action normally assigned by the model is to investigate the fire cues to determine the nature of the hazard, i.e. go to the room with the most smoke. However, there are exceptions which include the following situations: if the occupant has already completed an investigation; if the occupant has been in a room with moderate or bad smoke; if the occupant has been awakened or alexted by an occupant who has seen moderate or bad smoke; or if the occupant is an adult female and there is an infant who needs assistance.

If the exceptions do apply, the computer considers the following alternative actions in the order given below.

Help Occupant in Same Room. If more than one occupant qualifies for help, then the occupant who need to be alexted or awakened is given priority.

Help Occupant in Different Room. If there is a person in a different room who needs to be alerted or helped, the computer will make two assigrments: tentatively assign the fully capable occupant a person to alert, rescue or awaken; and assign the capable occupant the action of going to the room of that person. (Once he arrives at that room, a new action will be assigned based on the fire situation at that time and the capabilities of the persons in the room.) The priority order of these tentative assignments for helping persons in different rooms is: alert capable adult; rescue other occupant; wake other occupant; and alert child.

Investigate. If the occupant has not yet investigated nor otherwise "learned" of the danger of the fire, he will investigate.

Egress. If none of the above alternative assignments apply, the occupant is assigned the action of evacuating.

In this version of the model, an occupant over the age of ten functions as an adult.

A child who is 8,9 , or 10 will rescue any occupant in the same room and will go to another room to awaken or alert another occupant but will not go to another room for the purpose of rescuing an occupant. Children 
7 and younger do not assist othexs out of the building but will wake or alert other occupants who are older. A child is considered to be a baby if his age is equal to or less than the parameter BABY: babies do not initiate any actions. The tentative value of BABY is 3 .

The general rationale for the above priority order is to determine if there is a need for positive action, to assist those known to require help, and then to assist those who might require help. (A sleeping occupant can be considered as someone who might require help.) If two people are known to require help, provide help to the one needing more limited help, that is, a sleeping but otherwise capable occupant. The rule that supercedes all others is to help someone in the same room before helping an occupant in a different room.

\section{TRAVEL WITHIN THE BUILDING}

Occupants move within the building from node to node.

The route to be taken to a designated room, the best exit, or another designated node is determined by a shortest path algorithm. Normally when the occupant is investigating or going to assist another occupant, a straightforward shortest distance is determined. The shortest path to an exit (or after having been blocked by heavy smoke when going to assist another occupant) is based on a shortest path algorithm which assigns penalties or demerits for going through bad smoke and for leaving through windows. The path with the lowest number of demerits is selected. Each meter of travel is assigned one demerit, leaving by a window is assigned 100 demerits, and going to a node through bad smoke is assigned 200 demerits.

If the smoke at a node is intolerable, that node cannot be part of a route. If smoke is blocking all routes to the designated node (based on the criteria in Section 2), the occupant will decide to escape. If the occupant is escaping, the route out of the building with the least demerits is selected. If all escape routes are also blocked, he will be considered trapped.

\section{DELAYS, PAUSES AND ACTION TIMES}

Introduction. The time consuming activities of an occupant can be classified into three categories.

Movement from one node to another.

Delays and pauses. These activities include time to awaken, time to make decisions, and time to prepare for action.

Assisting actions, i.e., waking another occupant and preparing another occupant for egress.

Speed. A normal travel speed is set separately for each occupant. If it is set at 1.3 meters per second, then the folowing speeds apply:

$1.69 \mathrm{~m} / \mathrm{s}$ ( 30 faster than normal) if an occupant should consider the fire to be serious (e.g., he has been in a room with heavy smoke);

$0.65 \mathrm{~m} / \mathrm{s}$ ( 508 of normal) if the occupant is assisting another occupant, or $0.845 \mathrm{~m} / \mathrm{s}$ if he considers the fire to be serious;

$0.78 \mathrm{~m} / \mathrm{s}$ ( 608 of normal) if the smoke is bad (i.e., $\mathrm{S}>0.4$ ) and if the depth of the lower layer is less than 1.5 meters, i.e. if the 
occupant has to "crawl" under the smoke. $(0.52 \mathrm{~m} / \mathrm{s}$ if the occupant is also assisting another occupant.)

The normal travel speed and all the modification factors are parameters that can be set by the user. The choice of a normal travel speed of 1.3 meters per second is consistent with an extrapolation--to low levels of smoke--of Jin's data of people moving through smoke [Jin, 1976]. There are no data in the literature for travel speeds when people are concerned for their safety but the increased travel speed of $1.69 \mathrm{~m} / \mathrm{s}$ is not excessive since it is consistent with those found by Horiuchi as reported by Jin [Jin, 1976]. The decrease in the travel speed when $S>0.4$ is consistent with the findings of Jin for the case of irritating smoke. While Jin fitted his data with a curve, the step function for the decrease of speed at $S=0.4$, is not a major deviation from Jin's curve.

Whenever an occupant moves, his actions are printed on the screen and on the printer, recorded in a data file, and graphically represented on the screen. (Printing can be suppressed.)

Delay Times. The delay time, the decision time, and the time to perform assisting actions (hereafter, collectively called Delay Times) depend on the occupant characteristics, the fire characteristics and the impact of the fire cues on the occupant. The length of these Delay Times are determined by a set of decision rules. These Delay Times can be changed rather easily and all assigned values should be considered as tentative.

Minimum Response Time. The normal (i.e., smoke is not bad) minimum response (delay) time is 6 and 10 seconds for awake and sleeping occupants respectively: this includes decision and preparation time. These values are based on the work of Nober [Nober et al, 1981]. (If the smoke is bad, these times are reduced to 1 or 4 seconds,) The status of sleeping occupants is changed to awake status whenever the remaining response time is 6 seconds or less.

TPAUSE. An occupant is assigned normally a delay time of TPAUSE seconds whenever: he completes his investigation or terminates his movement along a route because of intolerable smoke; or changes his mind about helping another occupant. This delay includes the time required to choose a new action. TPAUSE is tentatively set equal to 3 seconds.

Time Required to Alert, Wake or Prepare for Evacuation. Whenever one occupant assists another, time for providing or receiving the service must be assigned. The times are a function of: the type of assistance; whether the occupant has encountered bad smoke (i.e., if he thinks the fire is serious); and age of the occupant needing assistance. The maximum time is 12 seconds to wake a disabled adult and to prepare him for evacuation under normal circumstances.

\section{SMOKE DETECTORS}

The building may have up to three smoke detectors. These smoke detectors are independent and are not interconnected in any way. It is necessary to provide the locations of the smoke detectors and how loud each detector would sound in each room of the building. A smoke detector will sound if the smoke density of the upper layer smoke is at least .015 , and the depth of the upper layex is .15 meters or greater.

An option in the program is to consider the smoke detectors as broken. It is, therefore, easy to determine the effect of smoke 
detectors by running the program twice with the same fire and occupants, once with smoke detectors working and once with them broken.

\section{CURRENT LIMTTATIONS AND FUTURE DEVELOPMENT}

The model as described in this paper is a preliminary version of a model under development. The development, improvement and expansion of the model is a continuing activity. The user should be aware of the limitations of the version of the model which was distributed in the summer of 1987. These limitations include:

1. The model is deterministic. Only typical behavior is modelled: aberrant behavior is not permitted.

2. Improved calibration is required to upgrade its validity. Calibration means changing parameter values in the model based on: a. analyses of data in the technical literature; $b$. judgments of experts; $c$. analyses of in depth interviews of survivors of residential fires; and, d. attempts to simulate behavior in real fire for which we have information.

3. Some typical actions are not included, e.g, fighting the fire.

4. Occupants respond to smoke conditions but not to heat conditions.

A recent addition permits the user to override the occupant decisions assigned by the computer. This permits the model to be used in studying the effect of alternative decisions by the occupants.

\section{REFERENCES}

1. Boring, E.G., "A History of Experimental Psychology" p. 289, Appleton-Century-Crofts, Inc. New York, 1950.

2. Jin, T., "Visibility through Fire Smoke (Part 5 Allowable Smoke Density for Escape from Fire)," Report of Fire Research Institute of Japan, No.42, September 1976.

3. Jones, W.W., "A Model for the Transport of Fire, Smoke and Toxic Gases (FAST)," NBSIR 84-2934, National Bureau of Standards, Gaithersburg, MD, 1984.

4. Keating, J.P. and Loftus, E.F., "Post Fire Interviews: Development and Field Validation of the Behavioral Sequence Interview Technique," GCR-84-477, National Bureau of Standards, Gaithersburg, Md., 1984. Interview records provided by the authors in private communication.

5. Levin, B.M., "Design as a Function of Responses to Fire Cues," General Proceedings of Conference: Research and Design 85: Architectural Application of Design and Technology Research, held at Los Angeles, California, March 14-18, 1985, pp. 289-294, American Institute of Architects Foundation, Washington, D.C., 1985.

6. Levin, B.M., "EXITT--A Simulation Model of Occupant Decisions and Actions in Residential Fires: Users Guide and Program Description," NBSIR 87-3591, National Bureau of Standards, Gaithersburg, MD, 1987.

7. Latane, B., and Darley, J.M., "Group Inhibition of Bystander Intervention in Emergencies, " Journal of Personality Psychology. Vo1.10, No. 3, pp. 215-221, 1968.

8. Licklider, J.C.R., "Basic Correlates of the Auditory Stimulus," in S.S. Stevens, Handbook of Experimental Psychology, p. 1031, John. Wiley \& Sons, Inc, New York, 1951.

9. Nober, E.H., et a1, "Waking Effectiveness of Household Smoke and Fire Detection Devices, "Fire Journal, Vo1.75, No.4, pp.86-91, 130, 1981 . 